\title{
Computed Tomography-guided Transthoracic Core Needle Biopsy of Lung Masses: Technique, Complications and Diagnostic Yield Rate
}

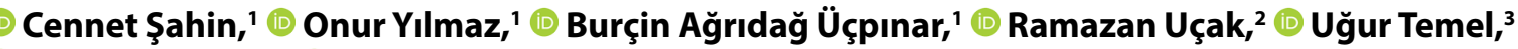 \\ Muzaffer Başak, 1 (i) Aylin Hasanefendioğlu Bayrak ${ }^{4}$ \\ 'Department of Radiology, Istanbul Sisli Hamidiye Etfal Training and Research Hospital, Istanbul, Turkey \\ 2Department of Pathology, Istanbul Sisli Hamidiye Etfal Training and Research Hospital, Istanbul, Turkey \\ ${ }^{3}$ Department of Thoracic Surgery, Istanbul Sisli Hamidiye Etfal Training and Research Hospital, Istanbul, Turkey \\ ${ }^{4}$ Department of Radiology, Istanbul Gaziosmanpasa Taksim Training and Research Hospital, Istanbul, Turkey
}

\begin{abstract}
Objectives: Computed tomography-guided core needle biopsy has an important role in the accurate histopathological diagnosis of lung masses. The present study aims to share our results of computed tomography-guided percutaneous core needle biopsy of lung masses.

Methods: A total of 117 patients had computed tomography-guided percutaneous core needle biopsy for lung masses between January 2017-September 2019 in our institution. In this study, these patients' post-procedural complications, diagnostic-yield-rates and radiological-histopathological correlations were evaluated retrospectively.

Results: Complications occurred in 23 (20\%) patients (20 (17\%) of pneumothorax; 3 (3\%) of hemorrhage). Chest-tube-drainage was needed in five (4\%) of all patients. No significant difference was found between complication rates and patient gender/age, tumor volume/localization or needle-path-length ( $p>0.05)$. In 77 of the $85(91 \%)$ primary-lung-cancer-cases radiological and pathological diagnostic results were correlated.

Conclusion: Computed tomography-guided core needle biopsy has a high diagnostic yield rate with acceptable complication rates in the diagnosis of lung masses.

Keywords: Computed-tomography-guidance; core-needle biopsy; fine-needle-aspiration biopsy; lung; transthoracic biopsy.

Please cite this article as "Şahin C, Yılmaz O, Ağrıdağ Üçpınar B, Uçak R, Temel U, Başak M, et al. Computed Tomography-guided Transthoracic Core Needle Biopsy of Lung Masses: Technique, Complications and Diagnostic Yield Rate. Med Bull Sisli Etfal Hosp 2020;54(1):47-51".
\end{abstract}

C omputed tomography (CT)-guided transthoracic needle-biopsy (CT-gTTNB) has an important role in the diagnosis of lung-masses. ${ }^{[1-5]}$ CT-gTTNB is less invasive compared to open-surgical-biopsy. ${ }^{[6]}$ Although the main reason for percutaneous-biopsy may be to differentiate benign from malignant, the reason may be to differentiate subtypes of lung cancer or metastasis. ${ }^{[7]}$ Due to the devel- opment in personalized-cancer-treatment, the diagnosis of molecular-subtypes has an important role. For example, in an advanced stage of non-small-cell lung cancer (NSCLC), testing for epidermal-growth-factor-receptor (EGFR) mutations and anaplastic-lymphoma-kinase (ALK) gene rearrangements is essential. ${ }^{[7-9]}$ Thus, obtaining sufficient tissue with CT-gTTNB is crucial for molecular-analysis. The supe- 
riority of core-needle-biopsy (CNB) to fine-needle-aspiration-biopsy (FNAB) in sampling with similar complication rates have been reported in several studies. ${ }^{[4,7,10]}$ In this study, we aimed to share the results of computed tomography-guided percutaneous core needle biopsy of lung masses performed in our institution.

\section{Methods}

This retrospective study was approved by our institution's ethical committee (Number 2329; Date: 02.04.2019). A total of 117 patients (88 (75.2\%) male, 29 (24.8\%) female) with a mean age of $63.7 \pm 9.8$ (age range: $37-88$ ) had CTguided transthoracic CNB between January 2017-April 2019 in single-center. The mean volume of the tumors was $74.3 \pm 125.11 \mathrm{cl}$ (min: 0.5; max: 688.0). Sixteen (13.7\%) of the masses were located centrally while 101 (86.3\%) of them were located peripherally. Patients were evaluated concerning biopsy-indication, lesion-localization, appropriateness for biopsy-procedure (parenchyma-capacity, hemogram-coagulation profile, antiplatelet-anticoagulant medication-use and capability for procedure). Contrast-enhanced thoracic CT and positron-emissiontomography-CT (PET-CT) images were evaluated before the biopsy. All the patients were informed about the biopsy-related-complications and informed-patientconsents were obtained. All the interventions were performed under CT-guidance (Toshiba, Alexion, Japan and Siemens, Somotom, Emotion, Germany) by two interventional-radiologists under sterile conditions. The safest and the shortest approach way and the most appropriate patient position (supine, prone or lateral decubitus) were planned before the biopsy procedure (Fig. 1). To reduce the risk of pneumothorax, the multi-puncture of the pleura was carefully avoided. All the procedures were performed under local anesthesia. The biopsy needle was placed in the most contrast-enhanced part or most FDGavid area of the tumor to avoid to sample the necroticareas. CNBs were performed using an $18 \mathrm{G}$ semi-automatic core-biopsy-needle (adjustable to $1 \mathrm{~cm}$ and $2 \mathrm{~cm}$ specimen-notch) through a $17 \mathrm{G}$ coaxial-needle (Fig. 2). To obtain a greater amount of tissues, at least two needle passes were performed in each biopsy with a single pleural puncture through a coaxial system. To prevent complica-

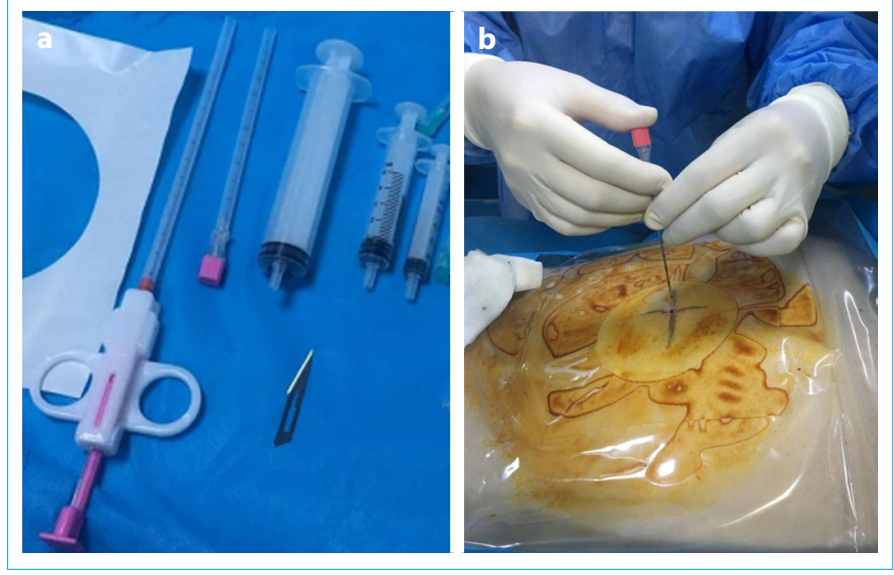

Figure 1. (a, b) An 18 Gauge semi-automatic needle and 17 Gauge coaxial needle were used for core biopsies under sterile conditions and local anesthetics (a). The safest and shortest approach was planned before the biopsy procedure. First, a 17G coaxial needle was inserted in the mass (b).
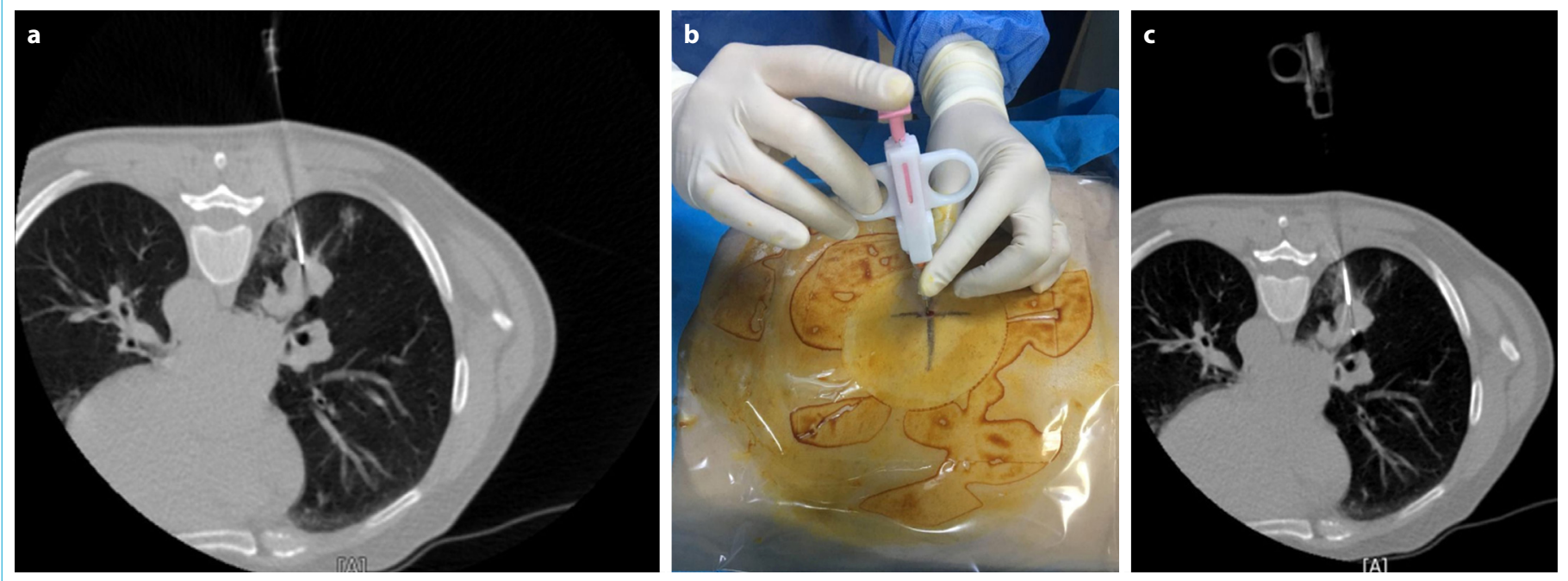

Figure 2. (a-c) Control CT scan was obtained to confirm before adjusting the needle that either the tip of the needle remains within the lesion or stops in a safe place (a). Then, an 18G semi-automatic core biopsy needle was sent through the coaxial needle (b). Since semi-automatic needle has an advantage due to the lightweight of the gun, a control CT scan was obtained after advancing the specimen notch into the mass before ring the biopsy needle (c). 
tion risk in CNB and to provide sufficiency, we had control CT scans to confirm before firing the needle that either the tip of the needle remains within the lesion or stops in a safe place. The samples were fixed in formalin (Fig. 3). All the specimens were evaluated by the same pathologist. The biopsy result was considered as non-diagnostic if the pathological evaluation failed to identify any specific diagnosis. Just after the biopsy, a control-CT scan of the biopsy area was obtained to assess the possible complications. Patients were observed in the hospital for about 3-hours, and control chest-radiography was obtained 3-hours after the biopsy. Post-procedural complicationrates, diagnostic-yield-rates and radiological-histopathological correlation were evaluated retrospectively. Also, relationships between the complications and the gender of the patients, the volume of the tumors, localization of the tumors (upper or lower lobes peripheric or central) and needle-path-lengths were evaluated.

For statistical analysis, Statistical Package for the Social Sciences (SPSS) for Windows (Version 21.0, Chicago, SPSS Inc.) program was used. Descriptive statistics were given as number and percentage for categorical variables and as mean, standard deviation, minimum, maximum and median for numerical variables. Ratios in independent groups were tested by Chi-Square Analysis. Statistical significance was defined as a $p$-value of $\leq 0.05$.

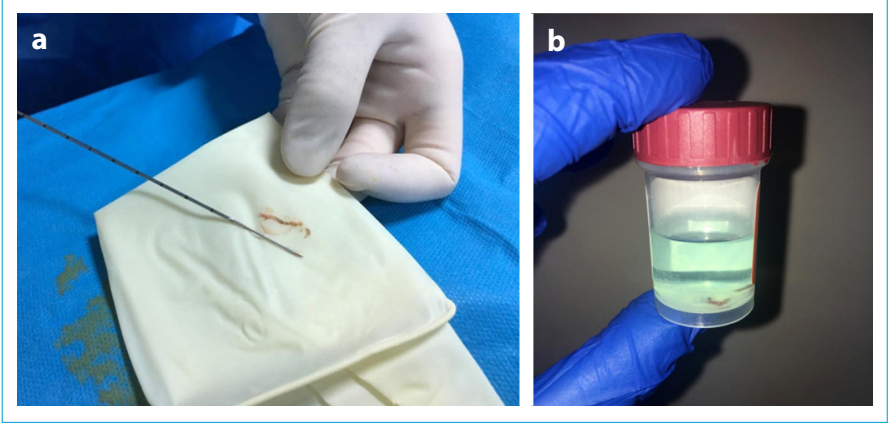

Figure 3. (a, b) The samples were checked for macroscopic adequacy (a) and were fixed in formalin (b).

\section{Results}

Complications occurred in $23(20 \%)$ patients (20 (17\%) of pneumothorax; 3 (3\%) of hemorrhage). Chest-tube-drainage was needed in five (4\%) of all patients. No statistically significant difference was found between complication rates and patient gender, patient age, tumor volume, lesion localization (upper or lower lobes, peripheric or central) and needle-path-length ( $p>0.05$ ).

A total of 106 (91\%) of the biopsy specimens had histopathological diagnostic adequacy for a molecular-analysis. In 77 of the $85(91 \%)$ of primary-cancer-cases and in 9 of the $10(90 \%)$ of metastatic-cases radiological and pathological diagnostic results were consistent (Fig. 4). The radiopathological diagnostic yield rates of the lesions are summarized in Table 1.

\section{Discussion}

In clinical practice, CT-gTTNB is used very often in the diagnosis of lung cancer with a procedure sensitivity of nearly 90\%. ${ }^{[1]}$ CT-gTTNB is a safe procedure with a mortality rate of lower than $0.05 \% .{ }^{[2]}$ Due to development in personal-
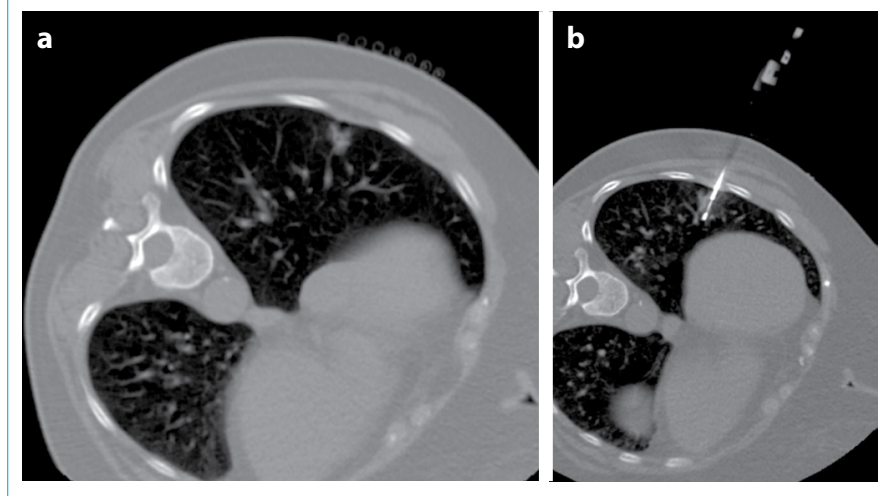

Figure 4. (a, b) A 58 years-old female with breast cancer history in the background. A $12 \mathrm{~mm}$ nodular lesion in the right lung was found suspicious for a primary lung cancer radiologically $(\mathbf{a}, \mathbf{b})$. Core-needle biopsy result revealed primary lung adenocarcinoma in this patient. Assessment of the radiological morphology of the masses is important in the differential diagnosis.

Table 1. The yield rates of the radiological diagnoses

\begin{tabular}{|c|c|c|c|c|c|}
\hline & \multicolumn{3}{|c|}{ Pathological diagnoses } & \multirow[b]{2}{*}{ Benign } & \multirow[b]{2}{*}{$\begin{array}{l}\text { Total number } \\
\text { of the patients }\end{array}$} \\
\hline & Non-diagnostic & Lung cancer & Metastasis & & \\
\hline \multicolumn{6}{|l|}{ Radiological diagnoses, n (\%) } \\
\hline Lung cancer & $9(75.0)$ & $77(90.6)$ & $1(10.0)$ & $6(60.0)$ & $93(79.5)$ \\
\hline Metastasis & $2(16.7)$ & $6(7.0)$ & $9(90.0)$ & $1(10.0)$ & $18(15.4)$ \\
\hline Benign lesion & $1(8.3)$ & $2(2.4)$ & $0(0.0)$ & $3(30.0)$ & $6(5.1)$ \\
\hline Total number of the patients, $\mathrm{n}(\%)$ & $12(100.0)$ & $85(100.0)$ & $10(100.0)$ & $10(100.0)$ & $117(100.0)$ \\
\hline
\end{tabular}


ized cancer therapy, to identify actionable mutations with greater amounts of tissue has an important role in the current molecular profiling era. ${ }^{[9]}$ In NSCLC, searching for EGFR-mutations and ALK-gene-rearrangements is essential. ${ }^{[7-9]}$ Thus, obtaining sufficient tissue with CT-gTTNB is crucial. Although sampling and diagnosis can be made either by $C N B$ or FNAB, CNB is superior in molecular-analysis because it provides more cellular tissue of samples than FNAB for genomic testing. ${ }^{[10]}$

Since it has an advantage due to the lightweight of the gun and giving an option of advancing the specimen-notch into the mass before ring the biopsy needle, a semi-automatic-needle was preferred for core-biopsy. ${ }^{[11]}$ To prevent complication risk in CNB and to provide sufficiency, a control-CT-scan was obtained to confirm the tip of the needle before firing that either it was remaining within the lesion or stops in a safe place. ${ }^{[11]}$ In this point of view, using a semiautomatic-needle was more advantageous compared to full-automatic-needle that full-automatic needle did not allow to have control CT-scan before firing the needle due to its high-weight. Also, another reason was that the tissue around the sampling lesion might have a trauma effect due to the vibration of the needle at the time of firing due to the bigger power of full-automatic-needle.

During $\mathrm{FNAB}$, an on-site cytologist may be required to improve the diagnostic-quality and reduce the number of passes. As we did not have an on-site cytologist in the clinic, CNB was preferred in all of the cases without minding the size of the masses due to its superiority in definite pathological-diagnosis. The overall diagnostic yield rate was $91 \%$, which was consistent with the literature. ${ }^{[2]}$ All the samples (out of non-diagnostic 11 (9\%) cases) that were obtained by CNB were adequate for the analysis of molecular-subtypes.

Accurate radiologic-pathologic correlation can lower the risk of over or under-diagnosis and can aid in optimal patient selection for CT-gTTNB. ${ }^{[13,14]}$ The radiological diagnosis had high positive-predictive-values (PPV) for primarylung-cancer and metastasis with rates of $91 \%$ and $90 \%$, respectively, in the current study.

The overall complication-ratio was $20 \%$, which was consistent with the literature. ${ }^{[2,15,16]}$ The most common procedure-related complications were pneumothorax and pulmonary-hemorrhage (as perilesional ground-glassopacity) with the incidence of $17 \%$ and $3 \%$, respectively. In five (25\%) of all pneumothorax cases (4\% of all cases), a percutaneous drainage-catheter or chest-tube placement was required, while none of the hemorrhage cases needed therapeutic consequences. There was no hemothorax, airembolism or patient mortality. In a meta-analysis, compli- cation rates for CNB and FNA were reported as 39\% and $24 \%$, respectively. ${ }^{[12]}$ In our study, complication-rates for CNB were not higher than the rates for either CNB or FNAB that have been reported in the literature. ${ }^{[2,11,15-17]}$ Although it is reported that the incidence of pneumothorax significantly increases with the decreasing size of the nodule, ${ }^{[15]}$ in this study, we found no significant correlation between the lesion volume and the complication-rates.

To prevent pneumothorax risk, reducing the number of crosses of pleural-surface and avoiding fissure or bullae, plugging of the needle tract, positioning the patient with the puncture-side down after the biopsy have been recommended by some authors as intraprocedural techniques in the literature. ${ }^{[2]}$ We used single pleural-puncture, avoided crossing pleural-fissure or bullae and positioned the patient on intervened-side down to prevent complications, too. Although we did not perform plugging of the needletract, our pneumothorax complication-rate was not higher than the literature.

As a shortcoming of this study, this is a retrospective study designed in a single center with a small patient group. The experience of the two radiologists in interventional radiology was different (4 years to 13 years), which may be an effect on complication rates. Comparative analysis (regarding the complication rates and diagnostic adequacy) could not be performed between the two radiologists because there was a large difference between the number of biopsies performed by two interventional radiologists. This study can be improved with a wider patient group designed as multicentric.

\section{Conclusion}

CT-guided core needle biopsy is a reliable and efficient method with acceptable complication rates in the differential diagnosis of the lung-masses. The radiological diagnosis had a high PPV in this study. Thus, CNB should be preferred in the diagnosis of lung masses due to its high diagnostic-yield-rate and acceptable complication rates.

\section{Disclosures}

Ethics Committee Approval: The Ethics Committee of Sisli Hamidiye Etfal Training and Research Hospital provided the ethics committee approval for this study (02.04.2019-2329).

Peer-review: Externally peer-reviewed.

Conflict of Interest: None declared.

Authorship Contributions: Concept - C.Ş., O.Y., B.A.U., R.U., U.T., M.B., A.H.B.; Design - C.Ş., O.Y., B.A.U.; Supervision - C.Ş., R.U., U.T., M.B., A.H.B.; Materials - C.Ş., R.U., U.T.; Data collection \&/or processing - C.S.., O.Y., R.U.; Analysis and/or interpretation - C.Ş., O.Y., B.A.U., A.H.B., M.B.; Literature search - C.Ş., O.Y., B.A.U.; Writing C.Ş., O.Y., B.A.U.; Critical review - C.Ş., M.B., A.H.B. 


\section{References}

1. de Margerie-Mellon C, de Bazelaire C, de Kerviler E. Image-guided biopsy in primary lung cancer: Why, when and how. Diagn Interv Imaging 2016;97:965-72. [CrossRef]

2. Winokur RS, Pua BB, Sullivan BW, Madoff DC. Percutaneous lung biopsy: technique, efficacy, and complications. Semin Intervent Radiol 2013;30:121-7. [CrossRef]

3. Alam S, Masood M, Ashraf T, Centini G. Audit of local CT-guided percutaneous lung biopsy for diagnostic adequacy and safety. Clinical Radiology 2016;71:S5. [CrossRef]

4. Tsai IC, Tsai WL, Chen MC, et al. CT-guided core biopsy of lung lesions: a primer. AJR Am J Roentgenol 2009;193:1228-35. [CrossRef]

5. Di Bardino DM, Yarmus LB, Semaan RW. Transthoracic needle biopsy of the lung. J Thorac Dis 2015;7:S304-16.

6. Manhire A, Charig M, Clelland C, Gleeson F, Miller R, Moss H, et al. Guidelines for radiologically guided lung biopsy. Thorax 2003;58:920-36. [CrossRef]

7. Tian P, Wang Y, Li L, Zhou Y, Luo W, Li W. CT-guided transthoracic core needle biopsy for small pulmonary lesions: diagnostic performance and adequacy for molecular testing. J Thorac Dis 2017;9:333-43. [CrossRef]

8. Zappa C, Mousa SA. Non-small cell lung cancer: current treatment and future advances. Transl Lung Cancer Res 2016;5:288-300.

9. Pakkala S, Ramalingam SS. Personalized therapy for lung cancer: striking a moving target. JCI Insight 2018;3:e120858. [CrossRef]

10. Guimarães MD, Marchiori E, Hochhegger B, Chojniak R, Gross JL.
CT-guided biopsy of lung lesions: defining the best needle option for a specific diagnosis. Clinics (Sao Paulo) 2014;69:335-40.

11. Yoshimatsu R, Yamagami T, Tanaka O, Miura H, Tanaka T, Suzuki T, et al. Comparison of fully automated and semi-automated biopsy needles for lung biopsy under CT fluoroscopic guidance. Br J Radiol 2012;85:208-13. [CrossRef]

12. Yao X, Gomes MM, Tsao MS, Allen CJ, Geddie W, Sekhon H. Fineneedle aspiration biopsy versus core-needle biopsy in diagnosing lung cancer: a systematic review. Curr Oncol 2012;19:e16-27.

13. Snoeckx A, Reyntiens P, Pauwels P, Van Schil PE, Spinhoven MJ, Parizel PM, et al. Radiologic-Pathologic Correlation in Lung Cancer Presenting as a Subsolid Nodule: Room for Improvement? Clin Oncol 2017;2:1290.

14. Piplani S, Mannan R, Lalit M, Manjari M, Bhasin TS, Bawa J. Cytologic-radiologic correlation using transthoracic CT-guided FNA for lung and mediastinal masses: our experience. Anal Cell Pathol (Amst) 2014;2014:343461. [CrossRef]

15. Heerink WJ, de Bock GH, de Jonge GJ, Groen HJ, Vliegenthart R, Oudkerk M. Complication rates of CT-guided transthoracic lung biopsy: meta-analysis. Eur Radiol 2017;27:138-48. [CrossRef]

16. Schulze R, Seebacher G, Enderes B, Kugler G, Fischer JR, Graeter TP. Complications in CT-Guided, Semi-Automatic Coaxial Core Biopsy of Potentially Malignant Pulmonary Lesions. Rofo 2015;187:697-702. [CrossRef]

17. Dogan N, Usca ZN, Unal D, Uygun I, Pasa AO, Sadıkoglu MY. Bilgisayarlı tomografi (BT) esliginde transtorasik igne biyopsisinin (TIB) komplikasyonları. Med Bull Sisli Etfal Hosp 2009:43;107-11. 